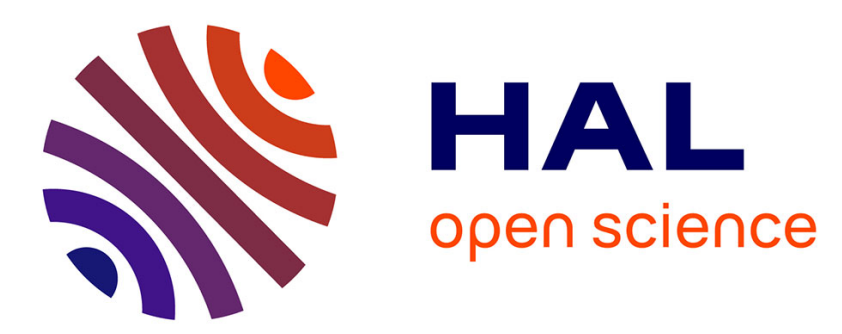

\title{
A tool to support resource allocation at small-to-medium seasonal airports
}

Bojana Mirkovic, Andrija Vidosavljevic, Vojin Tošić

\section{To cite this version:}

Bojana Mirkovic, Andrija Vidosavljevic, Vojin Tošić. A tool to support resource allocation at smallto-medium seasonal airports. Journal of Air Transport Management, 2016, 53 (Juin 2016), pp.54-64. 10.1016/j.jairtraman.2016.01.003 . hal-01263938

\section{HAL Id: hal-01263938 \\ https://hal-enac.archives-ouvertes.fr/hal-01263938}

Submitted on 28 Jan 2016

HAL is a multi-disciplinary open access archive for the deposit and dissemination of scientific research documents, whether they are published or not. The documents may come from teaching and research institutions in France or abroad, or from public or private research centers.
L'archive ouverte pluridisciplinaire $\mathbf{H A L}$, est destinée au dépôt et à la diffusion de documents scientifiques de niveau recherche, publiés ou non, émanant des établissements d'enseignement et de recherche français ou étrangers, des laboratoires publics ou privés. 


\title{
A tool to support resource allocation at small-to-medium seasonal airports
}

\author{
BojanaMirković $^{1}$, Andrija Vidosavljević ${ }^{2}$ and VojinTošić ${ }^{3}$ \\ ${ }^{1}$ University of Belgrade - Faculty of Transport and Traffic Engineering, Division of Airports and Air \\ Traffic Safety, Vojvode Stepe 305, Belgrade, Serbia; +381113091309, b.mirkovic@sf.bg.ac.rs; \\ corresponding author
}

${ }^{2}$ ENAC - Ecole Nationale de l'Aviation Civile, Laboratoire de Mathématiques Appliquées, Informatique et Automatique pour l'Aérien (MAIAA), 7 avenue Edouard-Belin CS 54005, 31055 Toulouse Cedex 4, France; andrija.vidosavljevic@recherche.enac.fr

${ }^{3}$ University of Belgrade - Faculty of Transport and Traffic Engineering, Division of Airports and Air Traffic Safety, Vojvode Stepe 305, Belgrade, Serbia; v.tosic@sf.bg.ac.rs

\begin{abstract}
During a few months of the year seasonal airports face the challenging task of maintaining service quality while dealing with heavy traffic, often being pushed to operate on the limit of their available capacity. Under such circumstances, efficient allocation and timely reallocation of physical and human resources is what keeps the service quality of airports at an acceptable level.

The paper describes a tool to support allocation of the physical resources, developed for particular seasonal airport falling in the range 1 to 5 million annual passengers. The tool is designed to work with the traffic schedule - to check it against existing constraints imposed by terminal building and apron area, and to assign the appropriate alert if any of the constraints are violated. Thus, the tool provides airport planners with a clear overview of the traffic situation. Its main function is to allow airport planners to check the effects of different actions to resolve particular constraints violations on the overall situation, before making the final decision. Due to non-disclosure agreement, the tool and its features are presented in the paper on somewhat modified example.
\end{abstract}

Keywords: seasonal airports, resource allocation, decision support, interactive tool 


\section{Introduction}

Demand at an airport is rarely distributed evenly throughout the year, month and/or day. It is typically characterized by (more or less pronounced) hourly, daily and/or monthly variations. (Ashford et al., 1997). Monthly variations are typically used to determine the extent to which an airport experiences seasonal concentrations. Seasonality arises from an increase in demand, usually connected to vacation seasons (summer or winter). It may also be imposed by events related to important holidays that may differ depending on the country, region, religion, etc. (Halpern, 2011).

Eurocontrol (2007) identified 39 European seasonal airports using the traffic from 2006 as a reference. Excepting "regular" seasonal airports where seasonality is driven by the tourist season (summer or winter) among these 39, there are six airports that experienced seasonality due to special events in 2006.

Figure 1 shows seasonal character of seven AENA airports ${ }^{1}$. The distribution of annual departures by month for year 2011 is given in the chart (source: AENA Estadisticas, 2011). There is a clear difference between high season (usually from $4^{\text {th }} / 5^{\text {th }}$ to $9^{\text {th }} / 10^{\text {th }}$ month of the year) and off-season traffic. Depending on the airport, the difference can be smaller (Alicante and Malaga) or bigger (Palma de Mallorca, Murcia and Reus), or even very extreme in high season, resulting in sharp peaks (Ibiza and Menorca).

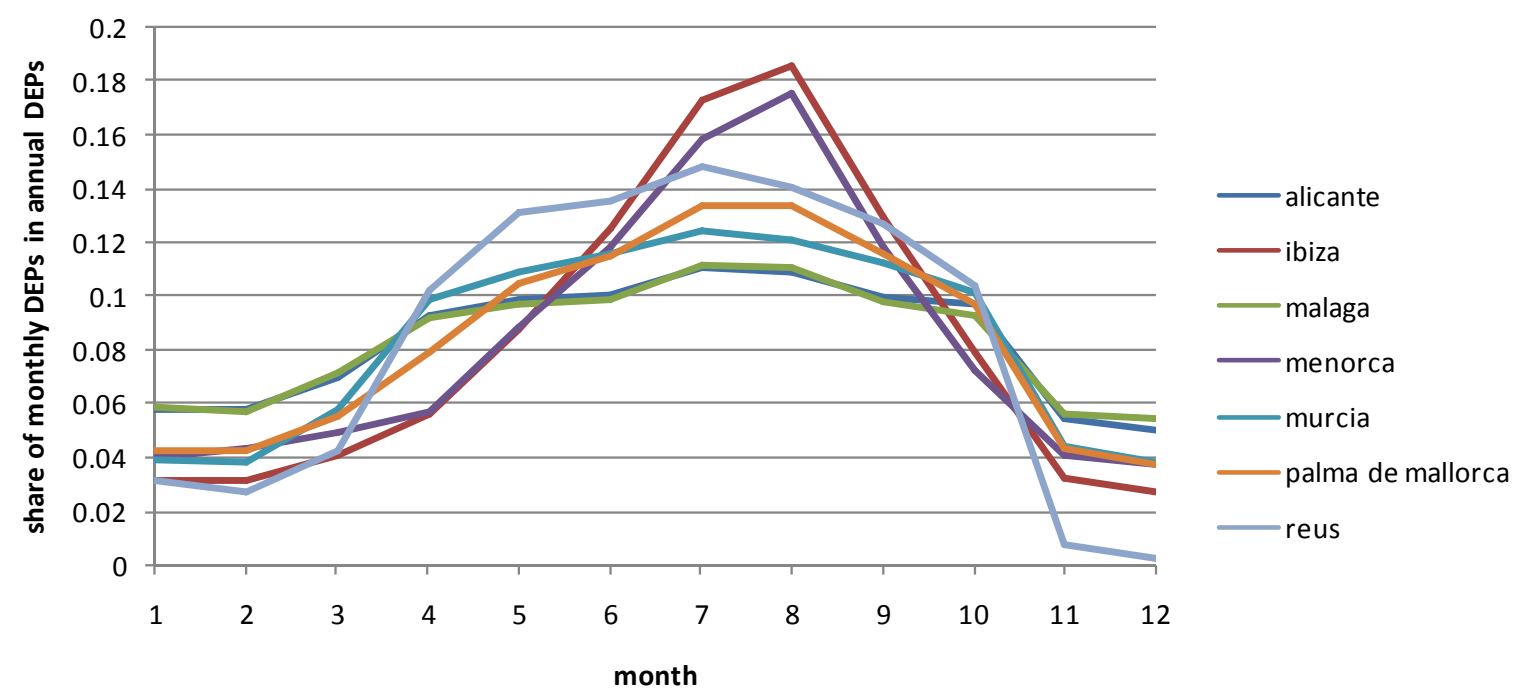

Figure 1 - Monthly distribution of annual departures in 2011 (compiled from: AENA Estadisticas)

During the high season, an airport is exposed to very high traffic demand, often being pushed to operate on the edge of its available capacity. During these few months of the year it is a challenging task for airports to maintain service quality (acceptable levels of efficiency, punctuality and delays). On the other hand, the available capacity is relatively (sometimes highly) underutilized outside the peak season, resulting in low productivity. Therefore, the

\footnotetext{
${ }^{1}$ Airports fall into different size categories: Palma de Mallorca and Malaga - 10 to 25 million passengers; Alicante and Ibiza - 5 to 10 million passengers; Menorca, Murcia and Reus -1 to 5 million passengers.
} 
successful management of a seasonal airport relies mostly on the efficient allocation of human and physical resources, both during the high season and off-season.

Slot allocation is one of the popular means to cope with airport congestion. It mainly refers to allocation of scarce capacity on the runway. But, in general, it can also be driven by congestion at other airside elements, such as terminal building and apron area. E.g. Katsaros and Psaraki (2012) address slot allocation at capacity-constrained airports with seasonal demand, on Greek airports example. They primarily focus on runway capacity congestion, as is the usual case. In this paper we offer a tool for physical (fixed) resource allocation, focusing on the cases at which the main bottleneck is at the terminal building and apron/gate area.

There are various industry tools available on the market ${ }^{2}$ developed for similar purpose, primarily to optimize gate assignment, but also for allocation of other fixed resources (checkin, baggage claim belts, etc.). However, these tools are usually not affordable for small-tomedium airports. An appropriate trade-off has to be achieved between airport needs and their readiness to invest in decision support tools. The tool presented in the paper (also in Mirkovic et al., 2013) offers affordable alternative product which is less sophisticated, but still can satisfactorily fulfil the requirements.

The tool is created to check traffic characteristics against different constraints that may appear at the terminal complex. It is meant to be used, firstly, in preparation for the season, once the expected traffic schedule in the winter/summer season is known. Airport planners can use the tool to perform preliminary resource allocation based on the given requirements and constraints. In the second run, the tool can be used on a weekly and daily basis to reallocate resources in order to respond on to traffic changes.

The same tool can also be useful for airports with a more regular distribution of demand throughout the year, in situations when they experience significant increases in traffic volume due to certain events (sports competitions, congresses etc.). Airports are faced with similar challenges when the terminal complex is under reconstruction and the usual traffic has to be handled with less capacity available.

Section 2 summarizes major constraints related to the terminal complex. Section 3 gives a description of the tool, and is organized in four sub-sections: the first one presents the case study airport; the second discusses the input data required by the tool; the third explains the graphical representation of the traffic data; and the fourth focuses on the alerts that the tool triggers when some of the constraints are violated. In Section 4 it is explained how to work with the tool and concluding remarks are given in Section 5.

\section{Terminal complex constraints}

Depending on the airport's infrastructure and characteristics of demand, there are various factors that can limit capacity of an airport. These may differ significantly from airport to airport. This paper focuses on the constraints that appear at the terminal complex. Airports with primarily passenger traffic are observed. ${ }^{3}$

\footnotetext{
${ }^{2}$ Offered by: Amadeus, Ascent Technology, Beontra, Seetek, Siemens, Sita, etc.

${ }^{3}$ Out of 528 airports in Europe 370 have only one dominant market segment, out of which $85 \%$ are passenger airports (Eurocontrol, 2007)
} 
Terminal buildings can serve different categories of traffic. It is common to differentiate between domestic and international terminals, or between units within the same terminal. Depending on the region, other specific terminal building modulation can apply, e.g. Schengen, non-Schengen, domestic, or inter-island (as is the case with airports of the e.g. Canary Islands), etc. Also, different terminal units or different levels of the same unit can be assigned to arrival and departure passenger flows. Terminals, terminal levels or terminal units allocated for different categories of traffic/traffic flows (domestic, international, arrival, departure, etc.) are hereinafter referred to as modules.

Capacity constraint in a terminal building, or any of the modules, can be imposed by any processing unit, in arrival or departure flow of passengers or bags, e.g. immigration (passport control), security areas, or baggage sorting areas, etc. Capacity constraints can be either global, imposed by centralized process (e.g. security control in departure flow), or local if they apply for particular module(s) (e.g. baggage claim in domestic terminal module). Depending on the structure of passengers flying to/from the airport (domestic, international, originating, terminating or transfer) and their distribution in time, the same terminal building can process different number of passengers per unit of time (and aircraft carrying the to/from the airport), because the capacity constraint moves from one module to another or from one processing unit to another. For example, while the airport is struggling with congestion in its international modules, due to passport control capacity constraints, the domestic module might be operating below its capacity.

Allocation constraints at apron/gate area refer to compatibility between aircraft type and aircraft stand size. Aircraft is allowed to occupy only the stands designed for the same or any bigger $^{4}$ aircraft type. For contact stands (gates) the same constraints apply as for the terminal building/module they are connected to (e.g. only international flights can be allocated at gates connected to international terminal). Terminals with vertical separation between traffic categories (e.g. one level for domestic, one level for international) allow more flexible usage of gates. Also, other apron areas may exist at the airport, e.g. maintenance apron, pilot school apron, or apron for any other special purpose. Although they are not available for passenger aircraft in regular conditions, these stands can be used for traffic overflow when necessary.

Given demand structure with respect to aircraft types and users, apron capacity depends on stand occupancy times. Stand occupancy time accounts for turnaround time and buffer (separation) time. Different aircraft, with respect to aircraft type and airline, require different turnaround times. During high season turnaround times can be constrained aiming to achieve higher apron capacity. In order to enable efficient aircraft flow across the apron it is necessary to provide buffer times between two consecutive occupancies of the same aircraft stand or apron area. Furthermore, it also assures that two aircraft are not assigned to the same aircraft stand simultaneously. Buffer time depends on apron taxiway/taxilane system (single bidirectional taxilane, parallel taxilanes, etc.).

Constraints at terminal complex can be classified as: allocation constraints related to aircraft stands and terminal modules, capacity constraints in terminal(s) and modules, and time constraints related to turnaround time and buffer time. For successful allocation of the resources they have to be observed all together. There is not sharp boundary between these classes. So, turnaround time is at the same time capacity constraint for apron area, while

\footnotetext{
${ }^{4}$ Larger wingspan
} 
buffer time is also allocation constraint as it prevents assignment of two aircraft on the same aircraft stand at the same time.

\section{Description of the tool}

The tool for resource allocation ${ }^{5}$ is designed to work with the traffic schedule and to check it against specific physical and operational constraints imposed by the terminal building and apron area at given airport. If any constraint is violated the tool sends an alert (in visual and descriptive form) to the airport planner, thus providing a clear overview of the conflicting situations that should be resolved.

The tool itself does not offer a solution to alert situations. It is up to airport planners to suggest one or more solutions, based primarily on their experience. At airports of small-tomedium size experienced airport planners, who are familiar with airport structure and operational limitations, as well as general traffic requirements, can easily "see" solutions to various conflict situations. However, due to the many constraining factors and their interactions, they can hardly realize the effects of their "local" actions on a global traffic situation. The main function of the tool is to enable airport planners' situational awareness at any time, and to allow them to check the effects of different actions, before making the final decision.

The tool is developed for Prince Mohammad Bin Abdulaziz International Airport, Madinah, Saudi Arabia. The goal was to provide support to cope with the traffic increase ${ }^{6}$ with existing resources at terminal/apron complex until new terminal/apron complex (located on the opposite side of the runway system) is built. Due to non-disclosure agreement this particular example could not be used to explain all the features of the tool and to demonstrate how it works. The tool can be, however, adapted to other airports given their physical and operational constraints at terminal complex. An academic example (MVT ${ }^{7}$ airport) is used in this paper, instead. It is described in the following section. ${ }^{8}$

\subsection{Physical and operational constraints at airport's terminal complex: case study airport}

MVT airport is hypothetical seasonal airport, assumed to be located inside the Schengen zone.

MVT's terminal building consists of six modules:

- M1 - for domestic flights - arrivals,

- M2 - for Schengen flights - both arrivals and departures and, when necessary, nonSchengen departures,

- M3 - for non-Schengen flights - arrivals,

- M4 - for non-Schengen flights - arrivals and departures,

- M5 - non-Schengen flights - arrivals, and,

- M6 - for domestic flights - departures.

\footnotetext{
${ }^{5}$ Developed in RAD Studio and compiled to run on the Windows platform

${ }^{6} 3.2$ million passengers in 2010; 4.6 million passengers in 2013

${ }^{7}$ MVT does not refer to Mataiva Airport in French Polinesa (MVT/NTGV), but it is a hypothetical airport

${ }^{8}$ One day traffic from Tenerife Sur airport is used as the traffic sample, 14.2.2013
} 
The majority of passengers that fly to/from the airport during high season are foreign nonSchengen tourists. Thus, the main bottleneck at the terminal building is at passport control in the arrival passenger flow.

All the constraints are defined in aircraft seats i.e. assuming a 100\% load factor, which is the worst-case scenario. At the first level of planning (seasonal level) the airport planner has to decide whether all aircraft intending to fly to/from the airport can be accepted or not. For that purpose, it is reasonable to work with seats, because load factors are not yet known. Later, when the tool is used for reallocation of resources on a daily basis, the number of seats can be (and it is desirable to do so) replaced with the number of passengers (obtained from booking data) in order to get more realistic results, instead of over-constraining already insufficient resources.

Terminal modules M1, M2 and M6 do not have passport control, and therefore have none of the constraints imposed by it. The available number of passport control desks at modules M3 and M5 allow a processing rate of 800 seats/h (each). Module M4 should be used only when it is necessary to accept traffic overflow. It allows the processing of only 300 seats $/ \mathrm{h}$.

Regardless of the category of arrival (domestic, Schengen, non-Schengen) there is a capacity constraint for the arrival flow imposed by baggage sorting and delivery system:

- 1,600 arriving international+domestic seats in any 30 min period, and

- 3,000 arriving international+domestic seats in any 60 min period.

There is a centralized security system for all the terminal modules. Due to this, there is a capacity constraint for the departure flow at the airport, in terms of number of total departing seats that may be processed in a 30 min and 60 min period:

- 1,800 departing international+domestic seats in any 30 min period, and

- 3,500 departing international+domestic seats in any 60 min period.

The apron area consists of 20 aircraft stands, out of which 9 stands (stands 1 through 9) are terminal stands (without air-bridges), and 11 stands (stands 10 through 20) are remote. Three (of the 11) remote stands are located by the maintenance hangar and are not available for regular turnaround, except under special circumstances.

In Table 1, the design aircraft and maximum wingspan are associated to each aircraft stand, describing the apron structure at MVT airport.

Table 1 - Apron structure of MVT airport

\begin{tabular}{llll} 
Aircraft stand & Design aircraft & Max wingspan & Description \\
\hline 1 & ATR72 & 27.5 & Terminal \\
$2,3,4$ & B737-800 & 36 & Terminal \\
5 & B747-400 & 65 & Terminal \\
6 & A300 & 45 & Terminal \\
7 & MD11 & 52 & Terminal \\
8,9 & B767-300 & 48 & Terminal \\
$10,11,12,13$ & A320 & 34.5 & Remote \\
$14,15,16$ & B767-300 & 48 & Remote
\end{tabular}


65

52

36
Remote

Maintenance

Maintenance

As its apron is exposed to heavy loads during high season, the airport constrains turnaround times depending on the destination and type of aircraft, as follows:

- Domestic flight - 45 min for narrow-body ${ }^{9}$ and 60 min for wide-body ${ }^{10}$ aircraft, and

- Schengen and non-Schengen flight - 60 min for narrow-body, and 75 min for widebody aircraft.

Required buffer time between two occupancies of the same stand is $10 \mathrm{~min}$.

Given terminal complex characteristics (physical and operational) are built in the tool in the development phase: attributes holding the size and allocation rules (size of aircraft stand, category of stands, allocation rules for terminals), capacity constraints (general, or by module) and time constrains (turnaround time, or buffer time).

Using the MVT airport as an example, the tool for resource allocation is explained in the remainder of the section, as follows:

- Input data - basic and additional; the way they are imported/inserted or derived;

- Graphical representation of the traffic situation - terminal and apron views, and

- Alerts for constraints violation - the way they are triggered; the form in which they are displayed on the screen.

\subsection{Input data - traffic schedules}

Input data are imported directly from the traffic schedule (prepared in a pre-defined form), and/or inserted/changed manually.

There are fifteen "parameters" that describe an aircraft/flight in the tool. Nine of them are basic data, necessary for the tool to run. The other six are descriptive data, providing additional information to the airport planer (e.g. air-carrier and origin/destination) or being derived from basic data (e.g. on-block time and take-off time).

The input data are (basic data are emphasized in bold): " registration " number, air-carrier, type of aircraft, aircraft stand, date, flight number, origin, landing time, on-block time (landing time + taxi-in time), destination, off-block time, take-off time (off-block time + taxiout time), category of flight, terminal module, number of seats (when available - number of arriving and departing passengers).

Some data, the registration number, air-carrier, type of aircraft and aircraft stand, are linked to an aircraft, while the other data refer to the arrival and/or departure segments of that aircraft. Flight numbers, landing/take-off times and the origin/destination clearly take different values for arrival and departure. However, the category of flight, terminal module and number of passengers (when replacing the number of seats) could also take different values before and after turnaround.

\footnotetext{
${ }^{9}$ Narrow-body aircraft are considered aircraft with wingspan up to, but not including $36 \mathrm{~m}$

${ }^{10}$ Wide-body aircraft are considered aircraft with wingspan equal to or greater than $36 \mathrm{~m}$
} 
The "registration" number is a key field for connecting the arrival and departure segments of the same aircraft, and for linking flight data (listed in the table) to its graphical representation in the charts. This field may be filled out with the real registration number of the aircraft (usually not known for pre-seasonal planning), or any other letter/number combination (e.g. $\mathrm{AB} 123)$. If omitted, it is automatically filled out with a unique ID assigned by the tool.

To simplify and validate data insertion, lookup lists are defined for the parameters that may take values from a (more or less) limited set of data at one airport: air-carrier, type of aircraft, origin/destination, flight category, terminal module and aircraft stand. Some of these fields are restricted and may accept only "values" from the list. In the case of MVT airport there are: six terminal modules (M1 to M6), 20 aircraft stands (1-20, as given in Table 1) and three categories of flights (SI - Schengen, NSI - Non-Schengen and D - Domestic). All other lookup lists (for air-carrier, aircraft type and origin/destination) are connected to tables in the database. They are not locked, and are easy to update/upgrade. The current database contains about 850 air-carriers, 55 aircraft types and 2800 airports (source: Airport Codes, 2013).

The date and number of seats are pre-defined data. The tool assigns default values if omitted to be filled, e.g. when adding a new flight, the tool automatically assigns the currently active date to it if no other date is specified. It is desirable to enter the exact number of seats for each aircraft (or, once it becomes available, the number of passengers on board). Otherwise, default values are automatically assigned: 300 seats for wide-body and 180 seats for narrow-body aircraft. Wide-bodies are D, E and F ICAO categories of aircraft (wingspan $36 \mathrm{~m}$ and more).

The arrival time is the time on the runway (landing time), while the time on the stand i.e. onblock time is calculated by adding taxi-in time. On the other hand, the departure time is the push-back time i.e. off-block time, while the take-off time is calculated by adding taxi-out time. Taxi-in and taxi-out times depend on the airport layout and may differ for different runways in use and aircraft stand locations. In the case study, an average taxiing time of $5 \mathrm{~min}$ is used for calculation, both for taxi-in and taxi-out, from any stand to both runways in use.

A screenshot of the traffic data tables is given in Figure 2. Five selected flights from the traffic sample ${ }^{11}$ are given in Table 2, with all 15 parameters in their exact order as displayed in traffic data tables Figure 2). They will be used in Section 3.4 to illustrate how alerts are triggered i.e. constraints violation check.

\footnotetext{
${ }^{11}$ for the demonstration purposes we used traffic schedule on 14.02.2013 at Tenerife Sur Airport, somewhat adapted for case study airport (and saved as 15.02.2013)
} 
Figure 2 - Traffic data tables

Columns 1-4 are related to aircraft data. Column 5 contains a description of the constraint violation, which will be explained later. Columns 6-10 are related to the arrival, and columns 11-15 to the departure of the same aircraft.

There are two traffic data tables (Figure 2) that, initially, contain the same data. Temporary table (white background) is the table airport planners work with, as it allows the changing of data. The main table (gray background) holds the initial state, allowing the airport planner to return to it when he/she needs it. More details are provided in Section 4.

Table 2 - Parameters for four selected flights from the traffic sample

\begin{tabular}{|l|l|l|l|l|l|}
\cline { 2 - 6 } \multicolumn{1}{c|}{} & 1 & 2 & 3 & 4 & 5 \\
\cline { 2 - 6 } \multicolumn{1}{c|}{} & REG & CARRIER & TYPE & STAND & ALERT DECR. \\
\hline I & EXS517 & JET2.COM LIMI... & Boeing 737-800 & 11 & (see 3.4 for details) \\
\hline II & NAX2412 & NORWEGIAN AS & Airbus A320-200 & 6 & (see 3.4 for details) \\
\hline III & AEA7146 & AIR EUROPA & Boeing 737-800 & 14 & (see 3.4 for details) \\
\hline IV & RYR5552 & RYANAIR & Boeing 737-800 & 10 & (see 3.4 for details) \\
\hline V & MON568 & MONARCH AIRL. & Airbus A330-200 & 5 & (see 3.4 for details) \\
\hline
\end{tabular}

\begin{tabular}{|l|l|l|l|l|}
\hline 6 & 7 & 8 & 9 & 10 \\
\hline ORIGIN & IN_CAT & LND_T & IN_SEATS & IN_TERMINAL \\
\hline NCL & NSI & $14: 20$ & 189 & 3 \\
\hline TRF & SI & $14: 30$ & 180 & 2 \\
\hline SCQ & D & $14: 30$ & 180 & 1 \\
\hline HHN & SI & $17: 50$ & 189 & 5 \\
\hline MAN & NSI & $17: 25$ & 374 & 4 \\
\hline
\end{tabular}

\begin{tabular}{|l|l|l|l|l|}
\hline 11 & 12 & 13 & 14 & 15 \\
\hline DESTINATION & OUT_CAT & OFF_BT & OUT_SEATS & OUT_TERMINAL \\
\hline NCL & NSI & $15: 20$ & 189 & 2 \\
\hline TRF & SI & $15: 20$ & 180 & 2 \\
\hline SCQ & D & $15: 30$ & 180 & 6 \\
\hline HHN & SI & $18: 20$ & 189 & 2 \\
\hline MAN & NSI & $18: 25$ & 374 & 4 \\
\hline
\end{tabular}

\subsection{Graphical representation of the traffic situation: terminal and aipron views}

Based on input data, the software displays the traffic situation at airport MVT, for a selected date, in the form of Gantt charts. The traffic situation of the current day is displayed by default. Two views/charts are available: terminal and apron.

Terminal view is a Gantt chart with the time line 00-24 (by default) on the horizontal axis and the six terminal modules on the vertical axis, as in Figure 3. In this view, aircraft are presented with two bars (arrival bar and departure bar), because incoming and outgoing passengers of the same aircraft may be assigned to different terminal modules. With this approach, it is also very easy to present the aircraft changing its flight "category" during its turnaround (e.g. arriving from a non-Schengen country, departing to a domestic destination). 
The bar length, both for arrivals and for departures, corresponds to aircraft turnaround time, with some exceptions. Aircraft having only a departure (early morning) or arrival segment (late night) are presented by the maximum turnaround time with respect to category of flight and aircraft type (narrow/wide body). Aircraft staying longer than $2.5 \mathrm{~h}$ at the airport are presented by an arrival bar and a departure bar, both with maximum turnaround time, with respect to category of flight and aircraft type (narrow/wide body). In this special case, the arrival bar starts at on-block time and ends at on-block + maximum turnaround time, and the departure bar starts at off-block - maximum turnaround time and ends at off-block time.

Using turnaround times to illustrate passengers' presence in the terminal, although very rough, does not have any repercussions on the calculations done to check the traffic against capacity constraints (see detailed explanation in section 3.4). More sophisticated representation would require detailed observations and analysis of passenger arriving and departing flows.

Figure 3 - Terminal view

Different categories of flights are given in different colours (see Figure 3):

- Gr e e n- for Schengen (SI)

- $\quad$ B l u e- for non-Scnhengen (NSI), and

- Purple- for Domestic (D).

Regardless of the flight category, the arrival bar is given in a darker, and the departure bar in a lighter shade of the colour. These colours apply when flights do not violate any of the constraints.

Apron view is a Gantt chart with the time line 00-24 (by default) on the horizontal axis and the 20 parking stands on the vertical axis ( 9 by the terminal without air-bridges, and 11 remote stands), as in Figure 4. Each aircraft stand is constrained by the wingspan of the 
design aircraft. Maintenance stands are displayed in a lighter (gray) colour, as they are not available to regular traffic under normal circumstances.

In the Apron view, aircraft are presented by one gray bar (in regular, conflicts free conditions). The bar length corresponds to aircraft turnaround time (see Figure 4). The vertical axis is scrollable, showing 11 stands at the time.

Figure 4 - Apron view

Both the Terminal and Apron view may be customized in relation to the time frame. Instead of the default 24-hour view, the planner may select a time period that is currently of interest to be displayed. Also, the planner may zoom in certain situations of interest.

\subsection{Alerts for constraints violation}

Having the wide range of physical and operational constraints built in the tool, and traffic schedules parameters contained in the traffic schedules, the tool can assign different alerts for constrain violation by comparing corresponding values/attributes as it will be described in the reminder of this section.

Alerts related to passenger arrival/departure flows are visible in the Terminal view, and those related to the apron area are visible in the Apron view. When there is a constraint violation, the entire bar of the questioned aircraft is coloured red/orange/yellow, depending on the alert type. Red is associated with highest priority alerts, orange for medium priority, and yellow for lowest priority alerts. If more than one alert is assigned to the same aircraft, the higher priority alert is visible in the chart.

Table 3 provides relevant data related to alerts: simplified notation used, a description of the alert, colour, and the view in which it is visible. In addition, aircraft with alerts are marked 
with $\Lambda$, for easy detection. The alert mark appears before the registration sign in the data tables (Figure 2).

Table 3 - List of alerts, description and appearance

\begin{tabular}{|l|l|l|l|}
\hline Simplified notation (code) & Full description & Colour & Displayed in \\
\hline Inward-30 by XX & $\begin{array}{l}\text { Inward total seats in } 30 \text { min interval } \\
\text { breached by XX number of seats }\end{array}$ & RED & Terminal view \\
\hline Inward-60 by XX & $\begin{array}{l}\text { Inward total seats in } 60 \text { min interval } \\
\text { breached by XX number of seats }\end{array}$ & RED & Terminal view \\
\hline Outward-30 by XX & $\begin{array}{l}\text { Outward total seats in } 30 \text { min interval } \\
\text { breached by XX number of seats }\end{array}$ & RED & Terminal view \\
\hline Outward-60 by XX & $\begin{array}{l}\text { Outward total seats in } 60 \text { min interval } \\
\text { breached by XX number of seats }\end{array}$ & RED & Terminal view \\
\hline YY-Inward by XX & $\begin{array}{l}\text { YY terminal module capacity } \\
\text { breached by XX number of seats }\end{array}$ & ORANGE & Terminal view \\
\hline ARR Segment & ARR segment allocated to wrong terminal & ORANGE & Terminal view \\
\hline DEP Segment & DEP segment allocated to wrong terminal & ORANGE & Terminal view \\
\hline Large AC & $\begin{array}{l}\text { Single aircraft with number of seats greater than } \\
\text { module capacity }\end{array}$ & YELLOW & Terminal view \\
\hline Buffer by XX/Overlap & Buffer time violation by XX min (or Overlap) & RED & Apron view \\
\hline AC Stand & Incompatible aircraft stand & ORANGE & Apron view \\
\hline Maintenance Stand & AC assigned to maintenance stand & ORANGE & Apron view \\
\hline TAT by XX & Turnaround time breached by XX of minutes & VELLOW & Apron view \\
\hline
\end{tabular}

There are three groups of constraints that the traffic is checked against in the tool: allocation constraints, time constraints and capacity constraint.

Allocation constraints refer to:

1. Compatibility between aircraft type and aircraft stand size,

2. Compatibility between traffic category/flow and terminal module,

3. Usage of other than passenger apron areas (if any).

On the apron, constraint on aircraft type vs. aircraft stand size is checked using the wingspan of the aircraft and maximum allowed wingspan of the aircraft stand. Wingspan of the aircraft is withdrawn from the database ${ }^{12}$, or $65 \mathrm{~m}^{13}$ wingspan is automatically assigned to those aircraft types which are not included in the database. For each aircraft stand maximum wingspan is defined as its size characteristics, and build in the tool according to Table 1 (column 3).

For any aircraft $i$ its compatibility with aircraft stand $j$ is checked with the condition (1):

WingSpan $_{i} \leq$ MaxWingSpan $_{j}$

\footnotetext{
${ }^{12}$ The database contains 55 aircraft types, along with their wingspans, and may be upgraded with new entries if necessary.

${ }^{13}$ It is the maximum wingspan that may be accepted at the apron.
} 
WingSpan $_{i}$ - wingspan of aircraft type $i$ (Table 2 - column 3)

MaxWingSpan $_{j}$ - the size of the aircraft stand $j$ (Table 2 - column 4)

If the wingspan of selected aircraft is larger than the maximum wingspan allowed on the aircraft stand, an alert for aircraft stand incompatibility is sent out.

For aircraft I and III (Table 2) it is checked:

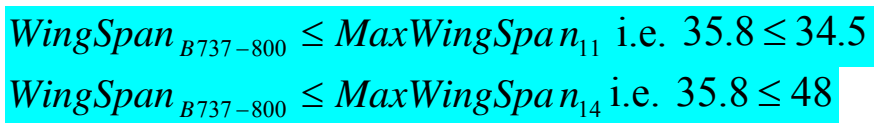

The condition is not satisfied for aircraft I and the alert AC stand will appear in Table 2 column 5 (see Table 4).

Table 4 - Alerts for four selected flights from the traffic sample

\begin{tabular}{|l|l|l|l|l|l|}
\cline { 2 - 6 } \multicolumn{1}{c|}{} & 1 & 2 & 3 & 4 & 5 \\
\cline { 2 - 6 } \multicolumn{1}{c|}{} & REG & CARRIER & TYPE & STAND & ALERT DECRIPTION \\
\hline I & EXS517 & $\begin{array}{l}\text { JET2.COM } \\
\text { LIMITED }\end{array}$ & Boeing 737-800 & 11 & $\begin{array}{l}\text { 3-Inward by 269 * AC Stand * } \\
\text { Buffer-Overlap }\end{array}$ \\
\hline II & NAX2412 & NORWEGIAN AS & Airbus A320-200 & 6 & Outward-30 by 165 \\
\hline III & AEA7146 & AIR EUROPA & Boeing 737-800 & 14 & TAT by 10 \\
\hline III & RYR5552 & RYANAIR & Boeing 737-800 & 10 & AC Stand * ARR segment \\
\hline IV & MON568 & MONARCH AIRL. & Airbus A330-200 & 5 & Large AC \\
\hline
\end{tabular}

Table 4 summarizes alerts for four selected flights from the traffic sample.

For other two allocation constraints, there are no numerical values to compare, but their descriptive attributes i.e. allocation rules are compared to corresponding traffic parameters.

If an aircraft is assigned to any of the maintenance stands (in this example 18, 19, 20) an alert Maintenance stand is given (regardless of aircraft type vs. aircraft stand size compatibility), because, in this case, maintenance stands are not available for regular use. In special occasions when this is allowed for traffic overflow, this alert should be ignored by airport planner.

A check is performed for each flight to determine whether it has been allocated a compatible terminal module, in accordance with terminal module allocation rules. If not, an alert for terminal module incompatibility appears.

In this example, there are six different terminal modules (M1-M6). Each module holds two attributes: segment (arrival or departure) and category of flight (domestic, Schenhen and nonSchengen). Inbound (Table 2 - column 7) and outbound (Table 2 - column 12) category of flight is compared to allocation rules of the module assigned (Table 2 - column 10 for inbound; and Table 2 - column 15 for outbound).

For example, aircraft I arrives from non-Schengen international destination, and departs to non-Schengen international. Its arrival flow is allocated to M3 (non-Schengen flights arrivals) and departure to M2 (for Schengen flights - both arrivals and departures and, when 
necessary, for non-Schengen departures). In both cases they are compatible, no constraint violation.

Aircraft IV, arrives from Schengen international and it is allocated to M5 that is nonSchengen international, which activates ARR Segment alert (see Table 4).

For aircraft flying to domestic destination, the tool activates DEP Segment alert if it would be allocated to any of arrival terminals: M1, M3 and M5; or to any departure terminal for other than Domestic flights: M2 and M4. Only if it assigned to M6 the alert is not activated (which is the case of aircraft III).

Time constrains refer to:

1. Turnaround time constraint, and

2. Buffer time required

The duration of turnaround times is checked against the maximum allowed turnaround time, depending on the flight category and type of aircraft.

Aircraft $i$ of class $j$ (wide-body or narrow-body) ${ }^{14}$, flying to destination that is of category $k$ (domestic or international), should satisfy the condition (2):

Turnaround $_{i} \leq$ MaxTurnaround $_{j k}$

Turnaround $_{i}=t_{i}^{D}-t_{i}^{A}$ - turnaround time of aircraft $i$

$t_{i}^{A}$ - ARR time i.e. on-block time calculated as: LND_time (Table $2-$ column 8$)+$ taxiing time (5 $\mathrm{min}$ in this example)

$t_{i}^{D}$ - DEP i.e. off-block time (Table 2 - column 13)

MaxTurnaround $_{j k}$ - maximum allowed turnaround time for aircraft class $j$ category $k$ (time constraint for given airport e.g. $45 \mathrm{~min}$ for narrow-body/domestic, or 60 min for narrow-body/international)

Otherwise, if aircraft intended to stay longer than max allowed turnaround time at the apron, the tool assigns a turnaround violation alert (TAT by $X X$ ).

For aircraft III (Table 2) the condition: $15: 30-(14: 30+00: 05) \leq 00: 45$ is not satisfied and TAT by 10 alert is given (see Table 4).

For aircraft I (Table 2$)$ the condition: $15: 20-(14: 20+00: 05) \leq 01: 00$ is satisfied, and there will be no alert in this case.

The buffer is planned to absorb expected regular disturbances in the traffic schedule on the day of operation (early arrival, short turnaround delays), accounting for the layout of the apron area, primarily apron taxiways/taxilanes system. In this example, the buffer constraint is considered as violated if the turnaround of the previous aircraft at the same aircraft stand is

\footnotetext{
${ }^{14}$ Wide-body aircraft: WingSpan $\geq 36 \mathrm{~m}$; narrow-body aircraft WingSpan $<36 \mathrm{~m}$
} 
still in process within the time-frame of $10 \mathrm{~min}$ before the arrival time of the aircraft in question.

It means that, for aircraft $i$, assigned to the same aircraft stand as aircraft $j$, where $t_{i}^{A} \geq t_{j}^{A}$, the time of arrival at aircraft stand for aircraft $i$ is equal or later than the arrival time for aircraft $j$, the condition (3) should be satisfied:

$t_{i}^{A} \geq t_{j}^{D}+10$

When the condition is not satisfied, but it is still $t_{i}^{A}>t_{j}^{D}$, the tool assigns an alert indicating the value of buffer violation $\left(t_{j}^{D}+10-t_{i}^{A}\right)$ in minutes (Buffer by $\left.X X\right)$. When it becomes $t_{i}^{A} \leq t_{j}^{D}$, it indicates that two aircraft overlap on the same aircraft stand (BufferOverlap).

Aircraft I (Table 2) is in collision with its predecessor allocated to same aircraft stand (11) BER3314. Scheduled on-block time of aircraft I $(14: 20+00: 05)$ is equal to scheduled offblock time of BER3314 (14:25). It means that no buffer is provided between these two aircraft. In this case Buffer-Overlap alert is assigned to aircraft I (see Table 4).

The most important purpose of the tool is to check the traffic against capacity constraints, but it would not be usable if allocation and time constraints are not checked in addition. In this example, there are five capacity constraints that apply at MVT airport:

1. Total number of inward/outward seats in $30 / 60 \mathrm{~min}$ period

2. Module capacity constraint (in this case applies only for M3, M4 and M5 due to passport control).

First one represents global constraints, while the second are local constraints.

For each aircraft the tool checks the time frames of $30 \mathrm{~min}$ and $60 \mathrm{~min}$ before ARR time $\left(t_{i}^{A}\right)$ and DEP time $\left(t_{i}^{D}\right)$ against global constraints regarding the number of inward and outward seats, respectively. Additionally, the $60 \mathrm{~min}$ time frame before ARR time is checked against local constraints i.e. passport control capacity constraints in this example. All constraints are checked according to the FCFS rule with respect to time of arrival (even when checking constraints against departing passengers).

For global constraints all aircraft caught in the 30/60 min time frame can be taken into consideration, but not necessarily included in the condition, as it will be shown below. In the case of local constraints only those aircraft served in the same module are observed.

Default capacity values (total, and per terminal module) are as given in the example. The tool allows the changing of default values, since this may be required under certain circumstances (e.g. some of the passport counters are out of service, a module is under reconstruction, etc.).

In Figure 5, the "mechanism" for triggering an alert is illustrated, on several examples. (It is assumed, for illustration purposes alone, that the arrival and departure bar of the same aircraft overlap.) 
Any aircraft $i$ is checked against 30 min inward seats constraint, with the condition (4):

$\sum_{j \in J} \operatorname{seats}_{j}^{A} \leq \operatorname{seats}_{30}^{A}, J=\left\{j \mid t_{i}^{A}-30 \leq t_{j}^{A} \leq t_{i}^{A}\right\}$

seats $_{j}^{A}$ - number of seats for aircraft $j$ or updated number of arriving passengers (when available); Table 2 - column 9

seats $_{30}^{A}$ - global capacity constraint in arrival flow in $30 \mathrm{~min}$ period (in our example 1,600 seats)

Only aircraft with an arrival time within the time frame are included in the calculation. If the condition is satisfied for each aircraft, it is assured that the system will be able to serve all incoming passenger-seats throughout a day.

For aircraft 6 in Figure 5 it applies:

seats $_{2}^{A}+$ seats $_{3}^{A}+$ seats $_{4}^{A}+$ seats $_{5}^{A}+$ seats $_{6}^{A} \leq 1,600$

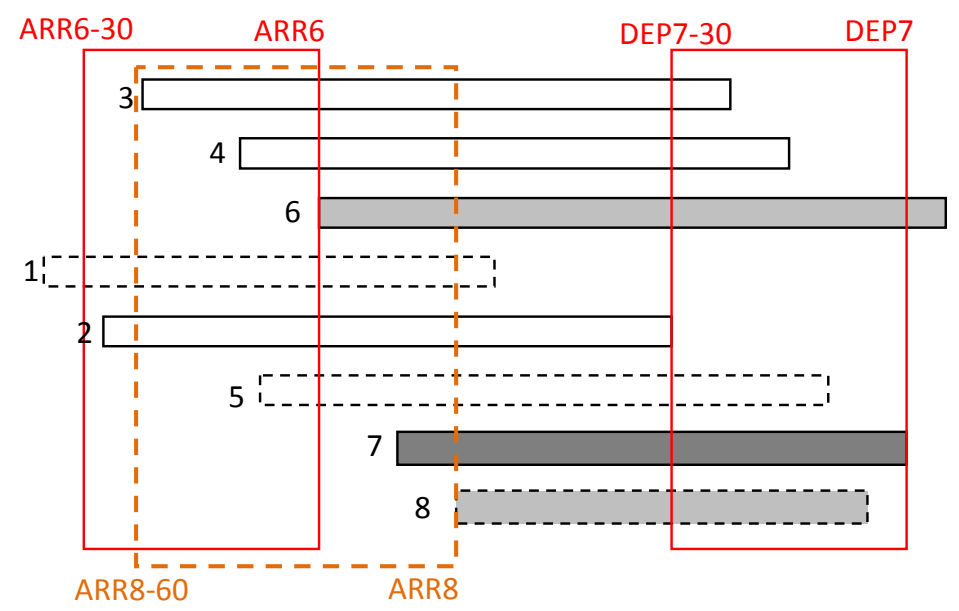

Figure 5- Examples operational constraints related to terminal view

Any aircraft $i$ is checked against 30 min outward seats, with the condition (5):

$\sum_{k \in K} \operatorname{seats}_{k}^{D} \leq \operatorname{seats}_{30}^{D}, K=\left\{k \mid t_{k}^{A} \leq t_{i}^{A}\right.$ and $\left._{k}^{D} \geq t_{i}^{D}-30\right\}$

seats $_{k}^{D}$ - number of seats for aircraft $k$ or updated number of departing passengers (when available); Table 2 - column 14

seats $_{30}^{D}$ - global capacity constraint for departure flow in $30 \mathrm{~min}$ period (in our example 1,800 seats) 
All aircraft having an arrival time before the arrival of the aircraft in question, and having a departure time within the time frame or after the departure time of the aircraft in question, are taken into consideration.

For aircraft 7 in Figure 5 it applies:

$$
\text { seats }_{3}^{D}+\text { seats }_{4}^{D}+\text { seats }_{5}^{D}+\text { seats }_{6}^{D}+\text { seats }_{7}^{D} \leq 1,800
$$

Aircraft 2 is not included in the condition because it departs before the time frame. Aircraft 8 is not included because its arrival time is later than arrival time of aircraft 7, which means that, following FCFS rule with respect to arrival times, this aircraft does not yet exists in the system.

The same applies to 60 min constraints, respectively for inward and outward (6) and (7) apply:

$$
\begin{aligned}
& \sum_{j \in J} \operatorname{seats}_{j}^{A} \leq \operatorname{seats}_{60}^{A}, J=\left\{j \mid t_{i}^{A}-60 \leq t_{j}^{A} \leq t_{i}^{A}\right\} \\
& \sum_{k \in K} \operatorname{seats}_{k}^{D} \leq \operatorname{seats}_{60}^{D}, K=\left\{k \mid t_{k}^{A} \leq t_{i}^{A} \text { and } t_{k}^{D} \geq t_{i}^{D}-60\right\}
\end{aligned}
$$

seats $_{30}^{A}$ - global constraint in arrival flow in 60min period (in our example 3,000 seats) seats $_{30}^{D}$ - global capacity constraint for departure flow in $60 \mathrm{~min}$ period (in our example 3,500 seats)

If the conditions are violated the tool assigns an alert for an inward/outward seats violation i.e. Inward-30 by XX, Inward-60 by XX, Outward-30 by XX or Outward-60 by XX (Table 3).

Any aircraft $i$, assigned to terminal module $M_{i}$, is checked against hourly capacity constraint with the condition (8): ${ }^{15}$

$$
\sum_{l \in L} \operatorname{seats}_{l}^{A} \leq \operatorname{seats}_{M i}^{A}, L=\left\{l \mid t_{i}^{A}-60 \leq t_{l}^{A} \leq t_{i}^{A} \operatorname{and}_{l}=M_{i}\right\}
$$

$$
\text { seats }_{M i}^{A} \text { - local/module capacity constraint in } 60 \mathrm{~min} \text { period (e.g. } 800 \text { seats/h for M3 and M5) }
$$

Assuming that flights 1, 5 and 8 (dash line bordered bars, Figure 5) are served by terminal module M3, the condition to check aircraft 8 with respect to the passport control constraint is as follows:

$$
\text { seats }_{5}^{A}+\text { seats }_{8}^{A} \leq 800
$$

If the condition is not satisfied, an alert for terminal module capacity violation is assigned to aircraft 8. Only aircraft allocated to the same module with an arrival time within the time frame are included in the calculation.

\footnotetext{
${ }^{15}$ This is the case when local constraint is on the passport control, i.e. in arrival flow. Different formulation of the condition would apply in one of the processing units in departure flow would impose local constraint.
} 
For example, aircraft I (Table 2) is given alert 3-Inward by 269, which holds the information that the demand for passport control in module M3 during $60 \mathrm{~min}$ period, upon arrival of this aircraft 8 will be for 269 seats/passengers higher than the capacity of this module.

Aircraft II is given the alert Outward-30 by 165 meaning that demand for service in observed 30 min period will be above baggage delivery system capacity by 165 expressed in seats/passengers.

It may happen that an aircraft has a number of seats that is larger than the capacity of the terminal module, meaning that the violation of hourly capacity comes from a single aircraft. In our example, this type of alert would only be triggered in the case of module M4 (300 seats/h), because the capacity of modules M3 and M5 (800 seats/h) cannot be breached by a single aircraft. Large aircraft alert (Large $A C$ ) is given to aircraft V (Table 2), since its number of seats (374) is above the capacity of module M4 to which it is allocated. This alert indicates that a capacity issue at M4 may be avoided by reallocating large aircraft to other terminal modules (M3 or M5, in this case). If, for any reason, it is not possible to change modules for the large aircraft, this alert suggests to the airport planner that he/she should allow additional time for passenger processing before assigning the next arriving aircraft to the same module.

\section{Working with the tool}

The column 5 of the traffic table (Figure 2; Table 4) holds the key information for airport planners. All alerts are also displayed in Terminal or Apron charts (as indicated in Table 3) and their priorities are differentiated by colours (red, orange and yellow). An alert is an indicator to airport planner where actions are needed to entirely avoid constraint violation (related to size and allocation rules; or overlapping on the same aircraft stand) or to bring them to lowest possible level in the case of capacity/time constraints.

Being interactive, not automated, the tool is meant primarily for experienced airport operation planners who already keep a wealth of solutions for different conflict situations "in their heads". However, due to the many constraining factors and their interactions, with an increase of traffic it becomes difficult, or even impossible, for them to imagine the effects of various local decisions/actions on a global traffic situation.

To resolve a conflict situation, an airport planner can: assign a different terminal module/stand; suggest a new landing/off-block time; reject the aircraft, or if the planner is aware that the constraint violation will not affect the system seriously, leave it as it is. For example, aircraft IV is given Large AC alert (Table 4), but airport planner can ignore it, if he/she is aware that no other aircraft is expected to be allocated to M3 module in next 20 min that will allow processing of all 374 passengers without causing congestion problems. Also, the alert Inward-60 by 100 can be ignored if airport planner knows that among the flights scheduled in observed 60 min interval there are those that traditionally carry less luggage by passenger than the average, so it will not cause congestion in baggage delivery area. Unlike Inward-60 by 100, as it refers to security check, and should not be brought above the capacity limits as it causes delays and decreases level of service in the building. Similarly, alerts related to AC stand, ARR segment, DEP segment or Buffer-Overlap, should not be ignored by airport planner at any time. 
Reallocation of the resources aiming to result in solving constraint violations is iterative process. So before making final decision airport planner may need to check the effects of various actions on the traffic situation throughout the day. As previously explained, Figure 2, current traffic situation is displayed in two tables - the main (upper half) and temporary (lower half). The temporary table is changeable, while the main table contains the current traffic situation. Airport planner uses temporary table to insert the changes and try their effects. When the desired changes are inserted in the temporary table, with the Re-Plan button these changes are visualized on the Apron and Terminal charts. If the airport planner is not satisfied with the outcome of one set of actions, he/she can easily return to the initial state ("stored" in the main table), by dismissing the current trial (the Cancel Temporary Changes button). Once the airport planner is satisfied with a solution, he/she accepts it with the Apply Changes button. This becomes the new current state, and is automatically re-written into the main table.

The tool also allows the changing of default capacity constraint values when it is necessary. The Change Constraint button activates a pop-up window, see Figure 6, where new temporary values can be inserted. The changes apply for a specified date, as they are connected to conditions at certain date/period (less counters, personnel, conveyor belt out of service, etc.).

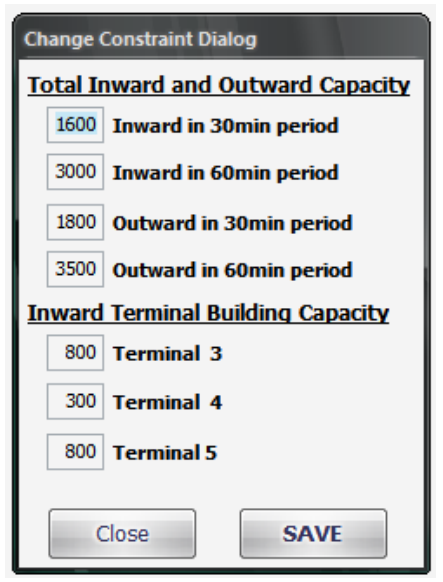

Figure 6 - Change constraint dialogue

All command buttons are available bellow traffic data tables (Figure 2).

\section{Concluding remarks}

The interactive resource allocation tool described in this paper is primarily developed for small-to-medium seasonal airports that operate under serious terminal and apron constraints during a few months of the season and, at the same time, have a complex traffic structure. The tool could also, on occasion, serve as a support to non-seasonal airports, when their demand temporarily approaches available capacity, driven by special events.

The tool complies with small-to-medium airport needs, on one hand, and their readiness to invest in decision support tools, on the other. It was adapted and applied at particular smallto-medium seasonal airport, up to 5 million passengers/year. Airports of similar size are in 
such a domain that an experienced airport operations planner, who is familiar with airport structure and operational limitations, as well as general traffic requirements, may see solutions to various conflict situations. However, due to the many constraining factors and their interactions, he/she can hardly realize the effects of different local actions (to resolve particular constraint violations) on a global traffic situation.

Areas for further improvement are primarily those related to constraints imposed by terminal building processes in passenger/baggage arrival and departure flows. For purposes of resource reallocation on a daily level, when passenger numbers are already known, the calculation should be improved, depending on which process is the bottleneck of the system (check-in, security, passport control, etc.). Improvements in this area require prior analysis of passenger flows through the terminal building, in order to get a notion of the time periods (after departure or before arrival) that passengers are expected to occupy a certain process.

\section{References}

[1] AENA Estadisticas, http://www.aena-aeropuertos.es/csee/Satellite/estadisticas/es (accessed May 7th, 2013)

[2] Airport Codes, http://www.photius.com/wfb2001/airport_codes_alpha.html (accessed May 7th, 2013)

[3] Ashford, N.J., Stanton H.P.M., Moore C.A. (1997) Airport Operations (2 ${ }^{\text {nd }}$ edition), McGraw-Hill, New York, U.S.

[4] Eurocontrol (2007) A Place to Stand: Airports in the European Air Network. Eurocontrol Trends in Air Traffic, Volume3, 2007

[5] Halpern, N. (2011) Measuring seasonal demand for Spanish airports: Implications for counter-seasonal strategies. Research in Transportation Business and Management, I, 47-54

[6] Katsaros, A., Psaraki, V. (2012) Slot misuse phenomena in capacity constrained airports with seasonal demand: the Greek experience, Transportation Planning and Technology, 35 (8), 790-806

[7] Mirkovic, B., Vidosavljevic, A., Tosic, V. (2013) A tool to support resource allocation at small-to-medium seasonal airports. $17^{\text {th }}$ Air Transport Research Society Conference, ATRS 2013, Bergamo, Italy, June 26-29, 2013 